\title{
Risk assessment of heavy landing based on BWM and cloud model
}

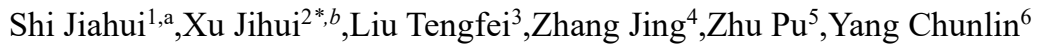 \\ ${ }^{1}$ Equipment Management and Unmanned Aerial Vehicle Engineering College Air Force Engineering University Xi'an,China \\ ${ }^{2}$ Equipment Management and Unmanned Aerial Vehicle Engineering College Air Force Engineering University Xi'an,China \\ ${ }^{3}$ Equipment Management and Unmanned Aerial Vehicle Engineering College Air Force Engineering University Xi'an,China \\ ${ }^{4}$ Equipment Management and Unmanned Aerial Vehicle Engineering College Air Force Engineering University Xi'an,China \\ ${ }^{5}$ Equipment Management and Unmanned Aerial Vehicle Engineering College Air Force Engineering University Xi'an,China \\ ${ }^{6}$ Air Traffic Control and Navigation College Air Force Engineering University Xi'an,China
}

\begin{abstract}
Aiming at the systemic, ambiguity and randomness characteristics of the aircraft's heavy landing risk, this paper starts from the system perspective and proposes a risk assessment method based on the BestWorst method (BWM) and cloud model. Aiming at the ambiguity and randomness of the information in the risk assessment, the cloud model is used to describe the language. In view of the difference in weights, combining BWM and cloud models for weighting. Finally, an example is given to ver ify the reasonableness and effectiveness of the model.
\end{abstract}

\section{Introduction}

Aircraft heavy landing risk refers to unsafe incidents that easily occur during the landing phase when the load exceeds the limit when the aircraft touches the ground, which may lead to accidents that cause damage to the aircraft body structure, and even serious flight accidents that cause damage to the aircraft. For heavy landing risk assessment, there are still the following problems: 1) Data processing lacks systematic and technical statistical analysis and research; 2) it is difficult to get rid of the limitations of the traditional expert empirical qualitative risk analysis and assessment model; 3) insufficient consideration of the large amount of ambiguity, randomness and cognitive uncertainty in the evaluation process. This paper proposes a risk assessment method based on BWM and cloud model.

\section{Basic theory}

\subsection{BWM algorithm description}

BWM is a new multi-factor evaluation method through a pairwise comparison matrix.The method steps mainly include the following steps.

- Define set $\left\{C_{1}, C_{2}, \cdots, C_{n}\right\}$ to describe the subject of evaluation

- $\quad$ Experts determine the factors $B$ and $W$ with the greatest and least impact and describe them as the best and worst factors.

- $\quad$ Determine the weight of the best factor $B$ to other factors according to the prescribed scale, and get the corresponding weight matrix $A_{B}=\left(a_{B 1}, a_{B 2}\right.$, $\left.\ldots, a_{B n}\right) . a_{B n}$ is expressed as the degree of importance of the best factor $B$ relative to the $n t h$ factor. .

- Determine the weight of other factors for the worst factor $W$ according to the prescribed scale, and get the corresponding weight matrix $A_{W}=\left(a_{1 W}, a_{2 W}, \ldots, a_{n W}\right) \cdot a_{B n}$ is expressed as the degree of importance of the $n t h$ factor relative to the worst factor $W$.

- Describe the optimal weight set as $\left\{w_{1}, w_{2}, \ldots\right.$, $\left.w_{n}\right\}$. The optimal weight set satisfies to minimize the maximum absolute difference of the set $\left\{\left|w_{B}-a_{B j} w_{j}\right|,\left|w_{j}-a_{j W} w_{W}\right|\right\}$.the problem is transformed into a nonlinear programming problem:

$$
\min \tilde{z} s . t\left\{\begin{array}{c}
\left|w_{B}-a_{B j} w_{j}\right| \leq \tilde{z} \\
\left|w_{j}-a_{j W} w_{W}\right| \leq \tilde{z} \\
\sum_{j=1}^{n} w_{j}=1, w_{j} \geq 0 ; \text { for all } j
\end{array}\right.
$$

Among them, $w_{B}$ represents the weight of the best factor $B$. $\quad w_{w}$ represents the weight of the worst factor $W$. $w_{j}$ represents the weight of the $J t h$ factor. $a_{B j}$ represents the importance of the best factor $B$ to the $J t h$ factor and $a_{j W}$ represents the $J$ th factor to the worst factor $W . \tilde{z}$ represents the lowest allowable deviation. 
The closer the $\tilde{z}$ value is to 0 , the smaller the error of the result and the more reliable it is.

\subsection{Cloud model algorithm description}

The cloud model is a model method that can realize the conversion between qualitative concepts and quantitative indicators. Generally, three digital features of Expected value, Entropy and Hyper entropy are used to describe the concept as a whole.

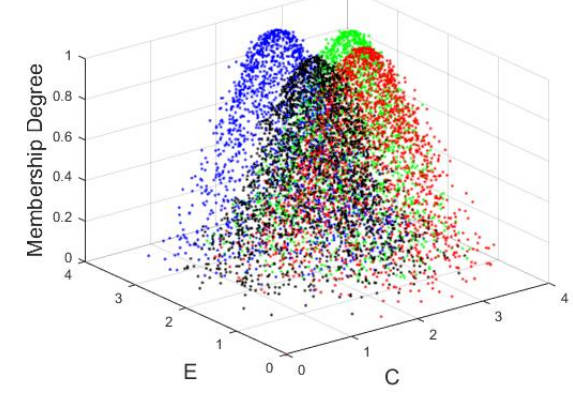

Figure 1 Multi-dimensional cloud model diagram

The five comment sets included in Cloud Conversion are as follows: $S=\left\{s_{0}=\operatorname{low}(\mathrm{L}), s_{1}=\right.$ moderately low(ML), $s_{2}=$ moderate $(\mathrm{M}), s_{3}=$ moderately high $\left.(\mathrm{MH}), s_{4}=\operatorname{high}(\mathrm{H})\right\}$.

$$
\begin{aligned}
& \tilde{y}_{0}=\left(E x_{0}, E n_{0}^{2}, H e_{0}^{2}\right)=\left(X_{\min }+3 E n_{0}^{2}, \frac{E n_{1}^{2}}{0.618}, \frac{H e_{1}^{2}}{0.618}\right) \\
& \tilde{y}_{1}=\left(E x_{1}, E n_{1}^{2}, H e_{1}^{2}\right)=\left(\begin{array}{l}
E x_{2}-0.382\left(E x_{2}-E x_{0}\right), \\
\frac{E n_{2}^{2}}{0.618}, \frac{H e_{2}^{2}}{0.618}
\end{array}\right) \\
& \tilde{y}_{2}=\left(E x_{2}, E n_{2}^{2}, H e_{2}^{2}\right)=\left(\begin{array}{l}
\frac{X_{\min }+X_{\max }}{2}, \\
0.382 \frac{X_{\min }-X_{\max }}{3(g+2)}, H e_{2}^{2}
\end{array}\right) \\
& \tilde{y}_{3}=\left(E x_{3}, E n_{3}^{2}, H e_{3}^{2}\right)=\left(\begin{array}{l}
E x_{2}+0.382\left(E x_{4}-E x_{2}\right), \\
\frac{E n_{2}^{2}}{0.618}, \frac{H e_{2}^{2}}{0.618}
\end{array}\right) \\
& \tilde{y}_{4}=\left(E x_{4}, E n_{4}^{2}, H e_{4}^{2}\right)=\left(\begin{array}{l}
X_{\text {max }}-3 E n_{4}^{2}, \frac{E n_{3}^{2}}{0.618}, \frac{H e_{3}^{2}}{0.618}
\end{array}\right)
\end{aligned}
$$

\section{Risk assessment of heavy landing based on BWM and cloud model}

The environment of aviation flight is constantly changing, especially for military aircraft, which have the characteristics of diverse models and complex tasks. The execution of flight tasks is affected by the environment, pilot operations, and aircraft status. In each stage of flight, the landing stage is very easy to cause errors and even lead to serious flight accidents.

According to the operating environment, the landing kinematics of the aircraft is analyzed, and four parameters of ground speed, ground pitch angle, ground vertical acceleration and ground distance deviation are selected to describe the results of the pilot's landing operation. This paper uses the key flight parameters as a benchmark for risk assessment and verification.

According to aircraft flight quality monitoring project specifications, operation manuals, training outlines and risk assessment procedures, the impact of risk factors is divided into 5 levels from I to V. The normalized values of the grading results are shown in Table 1.

Table1 Relative importance rating scale

\begin{tabular}{ccccc}
\hline $\begin{array}{c}\text { Degree of } \\
\text { infuence }\end{array}$ & Code & \multicolumn{3}{c}{ Cloud digital characteristics } \\
\cline { 3 - 5 } & $E x$ & $E n^{2}$ & $H e^{2}$ \\
\hline $\begin{array}{c}\text { Equally } \\
\text { important }\end{array}$ & I & 1.000 & 0.333 & 0.052 \\
$\begin{array}{c}\text { Moderately } \\
\text { important } \\
\text { important }\end{array}$ & II & 3.472 & 0.206 & 0.032 \\
$\begin{array}{c}\text { Quite } \\
\text { important }\end{array}$ & IV & 5 & 0.127 & 0.020 \\
$\begin{array}{c}\text { Extremely } \\
\text { important }\end{array}$ & V & 9.000 & 0.333 & 0.052 \\
\hline
\end{tabular}

\subsection{Risk factor cloud weight determination}

According to the language conversion in Table 1, the relative importance of the expert to the best factor relative to other risk factors can be represented by the cloud vector $\widetilde{A}_{B}=\left\{\tilde{a}_{B 1}, \tilde{a}_{B 2}, \tilde{a}_{B 3}, \tilde{a}_{B 4}\right\}$, and $\tilde{a}_{B j}$ represents the cloud representation of the importance of the best factor $W$ relative to the risk factor.

Construct a nonlinear programming solution for the cloud weight of each risk factor according to Equation 1.

$$
\min \tilde{z} \text { s.t }\left\{\begin{array}{c}
\left|\frac{\left(E x_{B}, E n_{B}^{2}, H e_{B}^{2}\right)}{\left(E x_{j}, E n_{j}^{2}, H e_{j}^{2}\right)}-\tilde{a}_{B j}\right| \leq\left(z_{1}, z_{2}, z_{3}\right) \\
\left|\frac{\left(E x_{j}, E n_{j}^{2}, H e_{j}^{2}\right)}{\left(E x_{W}, E n_{W}^{2}, H e_{W}^{2}\right)}-\tilde{a}_{j W}\right| \leq\left(z_{1}, z_{2}, z_{3}\right) \\
\sum_{j=1}^{n} E x_{j}=1, \text { for all } j \\
E x_{j} \geq 0, E n_{j}^{2} \geq 0, H e_{j}^{2} \geq 0 \\
z_{1} \geq 0, z_{2} \geq 0, z_{3} \geq 0 \\
\sim^{n}
\end{array}\right.
$$

Among them, $\tilde{z}=\left(z_{1}, z_{2}, z_{3}\right) \cdot z_{1} 、 z_{2} 、 z_{3}$ represent the minimum deviation allowable values corresponding to $E x_{j}, E n_{j}^{2}, H e_{j}^{2}$.

\subsection{Expert weight determination and comprehensive evaluation}

In the evaluation, each expert e evaluates the failure mode risk factors according to the scale. This paper constructs a 5-level scale for evaluation and converts it into a cloud parameter description. The scale is shown in Table 2. 
Table2 Risk assessment scale

\begin{tabular}{cccc}
\hline \multirow{2}{*}{ Probability of failure } & \multicolumn{3}{c}{ Cloud digital characteristics } \\
\cline { 2 - 4 } & & $E x$ & $E e^{2}$ \\
\hline Extremely high(EH) & 9.000 & 0.333 & 0.052 \\
High(H) & 6.528 & 0.206 & 0.032 \\
Moderate(M) & 5 & 0.127 & 0.020 \\
Relatively low(RL) & 3.472 & 0.206 & 0.032 \\
Low(L) & 1.000 & 0.333 & 0.052 \\
\hline
\end{tabular}

The $i$ th risk factor for the $j$ th failure mode of expert $l$ is transformed into a cloud vector $\tilde{X}_{j i}^{k}=\left(\tilde{x}_{j i}^{1}, \tilde{x}_{j i}^{2}, \ldots, \tilde{x}_{j i}^{k}\right.$, $\left.\ldots, \tilde{x}_{j i}^{l}\right)$.The evaluation weight w of the $k t h$ expert for the $i t h$ risk factor of the $j$ th failure mode is as follow:

$$
\left\{\begin{array}{l}
w_{j i}^{k}=\lim \frac{\sum_{q=1}^{l} d_{j i}^{k, q}}{\sum_{p=1}^{l} \sum_{q=1}^{l} d_{j i}^{p, q}}, q \neq k, q \neq p, l \geq 2 \\
w_{j i}^{k}, l=1
\end{array}\right.
$$

Obtain the weight matrix $\left(w_{j i}^{k}\right)_{m \times n}$ of expert $k$ for the $n t h$ risk factors of the $m t h$ failure modes.

$$
W^{k}=\left[\begin{array}{cccc}
w_{11}^{k} & w_{12}^{k} & \cdots & w_{1 n}^{k} \\
w_{21}^{k} & w_{22}^{k} & \cdots & w_{2 n}^{k} \\
\vdots & \vdots & \ddots & \vdots \\
w_{m 1}^{k} & w_{m 2}^{k} & \cdots & w_{m n}^{k}
\end{array}\right]
$$

The comprehensive assessment of the $m t h$ risk factor of the $n t h$ failure mode by expert $l$ is as follows.

$$
\tilde{x}_{j i}=\sum_{k=1}^{l} w_{j i}^{k} * \tilde{x}_{j i}^{k}
$$

After integrating all expert results, the cloud computing comprehensive evaluation matrix $\tilde{X}$ is obtained.

$$
\tilde{X}=\left[\begin{array}{cccc}
\sum_{k=1}^{l} w_{11}^{k} * \tilde{x}_{11}^{k} & \sum_{k=1}^{l} w_{12}^{k} * \tilde{x}_{12}^{k} & \cdots & \sum_{k=1}^{l} w_{1 n}^{k} * \tilde{x}_{1 n}^{k} \\
\sum_{k=1}^{l} w_{21}^{k} * \tilde{x}_{21}^{k} & \sum_{k=1}^{l} w_{22}^{k} * \tilde{x}_{22}^{k} & \cdots & \sum_{k=1}^{l} w_{2 n}^{k} * \tilde{x}_{2 n}^{k} \\
\vdots & \vdots & \ddots & \vdots \\
\sum_{k=1}^{l} w_{m 1}^{k} * \tilde{x}_{m 1}^{k} & \sum_{k=1}^{l} w_{m 2}^{k} * \tilde{x}_{m 2}^{k} & \cdots & \sum_{k=1}^{l} w_{m n}^{k} * \tilde{x}_{m n}^{k}
\end{array}\right]
$$

\subsection{Determine the risk leve I of heavy landing}

The product of the evaluation results of each risk factor is the final risk evaluation result.

$$
\begin{aligned}
& R P N^{*}=\prod_{i=1}^{n} F_{i}=\prod_{i=1}^{n}\left(\sum_{k=1}^{l} w_{j i}^{k} * \tilde{x}_{j i}^{k}\right) \\
& i=1,2, \cdots, 7 ; j=1,2, \cdots, m
\end{aligned}
$$

\section{Case Analysis}

The following takes a certain troop transport aircraft as an example, and conducts risk assessment on its landing data through the above method.

\subsection{Risk factor determination and empowerment}

During the risk assessment process, three experts were invited to evaluate the risk factors of the failure mode and the relative importance of the risk factors. This article converts the expert evaluation results of each risk factor into cloud parameters, and describes the calculation of cloud weights for all risk factors.

$$
(0.186,0.0517,0.0079)
$$

$W^{*}=(0.2217,0.0563,0.0086)$

$(0.1063,0.0334,0.0057)$

$$
(0.1537,0.0329,0.006)
$$

As shown in Table 3,the above weight determination method is used to determine the weight of each expert for all failure mode risk factors.

Table3 Expert weight of risk factors

\begin{tabular}{ccccc}
\hline $\begin{array}{c}\text { Ground speed } \\
\text { deviation }\end{array}$ & $\begin{array}{c}\text { Ground } \\
\text { elevation } \\
\text { deviation }\end{array}$ & $\begin{array}{c}\text { Ground } \\
\text { vertical } \\
\text { acceleration }\end{array}$ & $\begin{array}{c}\text { Ground } \\
\text { distance } \\
\text { deviation }\end{array}$ \\
\hline 1 & $0.5,0.5,0$ & $1 / 3,1 / 3,1 / 3$ & $0.17,0.45,0.41$ & $0,0.5,0.5$ \\
2 & $0.41,0.16,0.41$ & $0.10,0.36,0.44$ & $0,0.5,0.5$ & $0.5,0,0.5$ \\
3 & $0.41,0.41,0.16$ & $0.5,0,0.5$ & $0.5,0.5,0$ & $0.5,0.5,0$ \\
4 & $0.40,0.40,0.18$ & $0.18,0.41,0.33$ & $0.5,0,0.5$ & $0.39,0.10,0.21$ \\
5 & $0.5,0,0.5$ & $0.5,0.5,0$ & $0.5,0,0.5$ & $0.5,0,0.5$ \\
\hline
\end{tabular}

\subsection{Determination of the risk level of heavy landing}

According to the comprehensive evaluation calculation expert's comprehensive evaluation results are shown in Table 4

Table4 Comprehensive assessment of risk factors

\begin{tabular}{ccccc}
\hline $\begin{array}{c}\text { Ground speed } \\
\text { deviation }\end{array}$ & $\begin{array}{c}\text { Ground } \\
\text { elevation } \\
\text { deviation }\end{array}$ & $\begin{array}{c}\text { Ground vertical } \\
\text { acceleration }\end{array}$ & $\begin{array}{c}\text { Ground distance } \\
\text { deviation }\end{array}$ \\
\hline 1 & $1.2142,0.197$ & $1.9953,0.280$ & $0.5315,0.077$ & $0.7685,0.090$ \\
& $8,0.0629$ & $7,0.0837$ & $7,0.0267$ & $4,0.0305$ \\
2 & $0.9300,0.144$ & $1.3721,0.221$ & $0.6796,0.080$ & $1.0034,0.091$ \\
& $6,0.0454$ & $7,0.0688$ & $1,0.0265$ & $7,0.0291$
\end{tabular}




\begin{tabular}{ccccc}
\multirow{3}{3}{3} & $0.9300,0.157$ & $0.7697,0.128$ & $0.5315,0.078$ & $0.7685,0.112$ \\
& $8,0.0507$ & $0,0.0400$ & $4,0.0270$ & $9,0.0393$ \\
& $0.5745,0.150$ & $0.8002,0.189$ & $0.6939,0.063$ & $0.4499,0.099$ \\
4 & $9,0.0524$ & $9,0.0641$ & $7,0.0199$ & $3,0.0361$ \\
& & & $0.5315,0.049$ & $0.5336,0.076$ \\
5 & $0.6458,0.104$ & $0.7697,0.180$ & 0.076 & $2,0.0263$ \\
\hline
\end{tabular}

In order to verify the rationality and effectiveness of the model, the results of this paper are compared with the actual risk level, combined weighting cloud, and DS-cloud model evaluation results.

Table5 Heavy landing risk assessment results and comparison

\begin{tabular}{|c|c|c|c|c|c|c|c|c|c|}
\hline \multirow{2}{*}{$\begin{array}{c}\text { Heavy } \\
\text { landing } \\
\text { risk level }\end{array}$} & \multicolumn{5}{|c|}{ Grade membership } & \multirow{2}{*}{$\begin{array}{c}\text { Actual } \\
\text { grade }\end{array}$} & \multirow{2}{*}{$\begin{array}{c}\text { Combination } \\
\text { weighting normal } \\
\text { cloud model }\end{array}$} & \multirow{2}{*}{$\begin{array}{c}\text { Cloud } \\
\text { model-DS } \\
\text { theory }\end{array}$} & \multirow{2}{*}{$\begin{array}{c}\text { Interactive } \\
\text { multidimensiona } \\
\text { cloud model }\end{array}$} \\
\hline & $\mathrm{I}$ & II & III & IV & $\mathrm{V}$ & & & & \\
\hline 1 & 0.1332 & 0.4251 & 0.7741 & 0.9655 & 0.5694 & IV & IV & IV & IV \\
\hline 2 & 0.4365 & 0.8859 & 0.9487 & 0.8841 & 0.3002 & III & IV & III & III \\
\hline 3 & 0.8021 & 0.9871 & 0.7631 & 0.5037 & 0.1221 & II & II & II & II \\
\hline 4 & 0.9238 & 0.9125 & 0.6003 & 0.3599 & 0.0765 & I & I & I & I \\
\hline 5 & 0.8114 & 0.8848 & 0.5495 & 0.2111 & 0.0975 & II & II & II & II \\
\hline
\end{tabular}

According to the results in Table 5, the results of the method in this paper are roughly the same as the actual grades, and are basically consistent with the prediction results of the cloud model-evidence theory. The combined weighted normal cloud model is biased in the second evaluation due to excessive randomness. This verifies that the application of the model in heavy landing risk assessment is reasonable, feasible and accurate.

\section{CONCLUSION}

Aiming at the ambiguity, randomness and uncertainty in the heavy landing risk, this paper proposes a risk assessment method based on BWM and cloud model, and combines examples to illustrate. The main work is as follows.

1) Taking into account the systemicity and availability of risk factors, select the ground speed deviation, ground elevation deviation, ground vertical acceleration and ground distance deviation as the influencing factors of the heavy landing risk classification, and determine the five risk classification levels and classification standards to construct Risk classification system.

2) The BWM model is combined with the cloud model to calculate the relative weights of different risk factors, and the description weights are more realistic.

3) The independence of expert weights is determined. The weights depend on each expert's relative assessment of the risk factors of each failure mode, which avoids the defect of the average expert weight and makes the assessment results more accurate and reliable.

Foundation item: National Natural Science Foundation of China (52074309); national social science foundation (19XGL029)

\section{References}

1. Hadi Badri Ahmadi,et al.Assessing the social sustainability of supply chains using Best Worst Method[J].Resources, Conservation \& Recycling,2017,126:99-106.

2. Jafar Rezaei. Best-worst multi-criteria decisionmaking method: Some properties and a linear model[J].Omega,2016,64:126-130.

3. Zikang Su, Chuntao Li, Honglun Wang. Barrier Lyapunov function-based robust flight control for the ultra-low altitude airdrop under airflow disturbances $[\mathrm{J}]$.Aerospace $\quad$ Science And Technology,2019, 84:375-386.

4. Xinlong Li, Yan Ran, Genbao Zhang, et al.A failure mode and risk assessment method based on cloud model[J].Journal of Intelligent Manufacturing,2019,:1-14.

5. WANG L,GUO S G,REN Y.Landing operation risk evaluation based on the normal cloud of the flight data[J].Journal of Safety and Environment,2019,19(5):1555-1561.

6. WEI B W,HUANG H P,XU Z K.Two-dimensional evaluation model of rock mass based on combination weighting and cloud model[J]. Chinese Journal of Rock Mechanics and Engineering,2016,35(S1):3092 -3099 .

7. WANG L,SUN R S,WU C X.A flight QAR data based model forhard landing risk quantitative evaluation[J].China Safety Science Journal,2014,24(2):88-92.

8. JIAO,HUDSON J A. The fully-coupled model for rock engineering systems[J].International Journal of Rock Mechanics \& Mining Sciences \& Geomechanics Abstracts, 1995,32(5):491-512.

9. Wang S C,Jia X S,Hu Q W,et al.Effectiveness evaluation for equipment maintenance support system based on normal grey cloud model[J].Systems Engineering and Electronics.2019,41(07):1576-1582.

10. PENG H G,ZHANG H Y,WANG J Q.An uncertain Znumber multicriteria group decision-making method 
with cloud models[J].Information Sciences, 2019,501:136-154.

11. Sun X Y, ZHANG J Y,HAN G.Application of a grey cloud model in the identification of defects in bolt anchorage[J].INSIGHT,2019,61(8):465-471. 